\title{
On the Dynamics of Transient Plasmas Generated by Nanosecond Laser Ablation of Several Metals
}

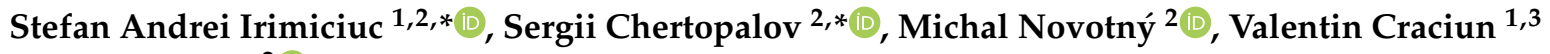 \\ and Jan Lancok ${ }^{2}$ (D) \\ 1 National Institute for Laser, Plasma and Radiation Physics-NILPRP, 409 Atomistilor Street, 077125 Magurele, \\ Romania; valentin.craciun@inflpr.ro \\ 2 Institute of Physics of the Czech Academy of Sciences, Na Slovance 2, 18200 Prague, Czech Republic; \\ novotnym@fzu.cz (M.N.); lancok@fzu.cz (J.L.) \\ 3 Extreme Light Infrastructure for Nuclear Physics, IFIN-HH, 077125 Magurele, Romania \\ * Correspondence: stefan.irimiciuc@inflpr.ro (S.A.I.); chertopalov@fzu.cz (S.C.)
}

Citation: Irimiciuc, S.A.;

Chertopalov, S.; Novotný, M.;

Craciun, V.; Lancok, J. On the

Dynamics of Transient Plasmas

Generated by Nanosecond Laser

Ablation of Several Metals. Materials

2021, 14, 7336. https://doi.org/

$10.3390 / \mathrm{ma} 14237336$

Academic Editor: Alina A. Manshina

Received: 1 November 2021

Accepted: 26 November 2021

Published: 30 November 2021

Publisher's Note: MDPI stays neutral with regard to jurisdictional claims in published maps and institutional affiliations.

Copyright: (c) 2021 by the authors. Licensee MDPI, Basel, Switzerland. This article is an open access article distributed under the terms and conditions of the Creative Commons Attribution (CC BY) license (https:// creativecommons.org/licenses/by/ $4.0 /)$.

\begin{abstract}
The dynamics of transient plasma generated by UV ns-laser ablation of selected metals $(\mathrm{Co}, \mathrm{Cu}, \mathrm{Ag}, \mathrm{Bi})$ were investigated by the Langmuir Probe method in angle- and time-resolved modes. Multiple ionic and electronic structures were seen for all plasmas with some corresponding to anions or nanoparticle-dominated structures. The addition of an Ar atmosphere energetically confined the plasma and increased the charge density by several orders of magnitude. For pressure ranges exceeding $0.5 \mathrm{~Pa}$ fast ions were generated in the plasma as a result of Ar ionization and acceleration in the double layer defining the front of the plasma plume. Several correlations between the target nature plasma properties were attempted. The individual plasma structure expansion velocity increases with the melting point and decreases with the atomic mass while the corresponding charged particle densities decrease with the melting point, evidencing the relationship between the volatility of the sample and the overall abated mass.
\end{abstract}

Keywords: laser produced plasmas; metals; Langmuir probe; plasma-target correlation

\section{Introduction}

Laser ablation of metals has been the focus of several studies in the past 30 years. The outcome of those studies has impacted both the fundamental knowledge of the laser ablation process and important applications like pulsed laser deposition [1,2], nanoparticle generation [3,4], laser patterning [5], or compositional analysis [6,7]. Several theoretical routes were developed to model the laser ablation of metals. Zighilei et al. [8,9], developed a model based on atomistic modeling considering phenomena like melting, spallation and phase explosion while Bykov et al. [10] developed a hybrid model based on integrating the thermal problem with Monte Carlo simulation and later updated the model for the ultrashort laser ablation of $\mathrm{Cu}, \mathrm{Ag}$ and W. Luney et al. [11] developed a model that considers the vaporization of the metals and post ablation ionization, while Wood et al. [12] developed a multiple scattering hydrodynamic model to describe the dynamics of ablation plasmas expanding in a background gas. Although the theoretical modeling sometimes can be aimed at understanding the fundamentals of the ablation process exclusively, there are some experimental studies attempting to find a correlation between plasma composition and dynamics and the irradiated targets. Baraldi et al. [13] investigated the dynamics of metallic ions $(\mathrm{Au}, \mathrm{Cu}, \mathrm{Ag}, \mathrm{Al}, \mathrm{Bi})$ generated by $\mathrm{UV}$ ns laser ablation at fluences up to $15 \mathrm{~J} / \mathrm{cm}^{2}$ and found that the ablated yield decreases with the melting temperature (or cohesive energy) of the metals. Similar dependence on the cohesive energy was reported by Therstrup et al. [14] and Salle et al. [15] which used alternative approaches to assess the ablation efficiency in UV-ns laser ablation of metals as functions of the ablation yield (ablated mass) of the cohesive energy (melting point). Konomi et al. [16] investigated 
the angular distribution dependence of the plasma properties in the case of metallic targets. The authors concluded that the low atomic mass elements have a wider angular distribution, results confirmed in [17] when the ablation of a complex multi-element target was investigated. In recent years Anoop et al. [18-20] and our group [21-26] used extensive diagnostic investigations on metallic plasma and revealed clear dependence of some plasma parameters on the melting point, atomic mass, or electrical conductivity of the material. The reports are general and cover several irradiation regimes (fs, ps, ns) and a wide range of materials ( $\mathrm{Al}, \mathrm{Cu}, \mathrm{Mn}, \mathrm{Ni}$, In, Te, W, Zn, Ti).

A significant part of available results on the target-plasma relation is given through the implementation of the Langmuir probe method in its time-resolved [24] or collector [27] versions. We recently showed that for the case of pulsed laser deposition (PLD) in specific conditions the information extracted from the saturation current of the probe can be limited without the implementation of complementary, usually more expensive techniques (high resolution optical emission spectroscopy, mass spectrometry, etc.). In $[24,25,28]$ we proposed the time and angle-resolved analysis of unbiased Langmuir Probe (LP) as an alternative to the usual approach, which has the advantage of offering more precise information relating to the internal structure of the ionic current, which is not possible in the saturation regime and gives the possibility to study both positive and negative charges from the ablated plasma. Recently, the method was shown to be sensitive to Ag oxidation processes in the plasma volume for pressure as low as $0.5 \mathrm{~Pa}$.

This paper used the LP for angle- and time-resolved analysis to investigate common trends in transient plasmas generated by ns-laser ablation of metals. The charge velocity distribution of plasma along various expansion angles was used to investigate the ion and electron distribution. The effect of Ar gas on the dynamics of metallic plasma was also studied and specific thresholds of gas ionization were found. By using a semi-empirical model, we calculated the neutral plasma density and plasma core temperature and we correlated them with the melting point and atomic mass of the targets. Other several target-plasma correlations were also found for electron temperature, charge density and expansion velocity.

\section{Materials and Methods}

A Surelite III Nd:YAG laser (wavelength-266 nm, repetition rate- $10 \mathrm{~Hz}$, fluence$3.8 \mathrm{~J} / \mathrm{cm})$ was focused on several metallic targets $(\mathrm{Co}, \mathrm{Cu}, \mathrm{Ag}, \mathrm{Bi})$. The targets were continuously rotated to avoid local heating and deep crater formation. The target-tosubstrate and LP distances were $50 \mathrm{~mm}$ and $37 \mathrm{~mm}$, respectively. The plasma investigations were performed under a residual vacuum of $5 \times 10^{-5} \mathrm{~Pa}$ and at $5 \times 10^{-2}, 5 \times 10^{-1}, 2,5$, and $10 \mathrm{~Pa}$ Ar pressure. Each experiment was preceded by a target surface cleaning procedure during which the LP was shielded from the incoming transient plasma while the rotating target was laser irradiated with 1200 pulses (for other details on the setup geometry, see Figure 1). The signal from the tungsten LP (diameter $-0.2 \mathrm{~mm}$ and exposed length $-2 \mathrm{~mm}$ ) was measured by collecting the voltage signal across a load resistor with a Tektronix DPO 4104 Digital Phosphor Oscilloscope (1 GHz, 5 GS/s, Tektronix Inc. Beaverton, OR, USA). All performed investigations were time-synchronized by a fast silicon photodiode (Thorlabs FDS100, Thorlab, Dortmund, Germany), and the initial measuring moment was considered to be the moment when the laser was fired. 


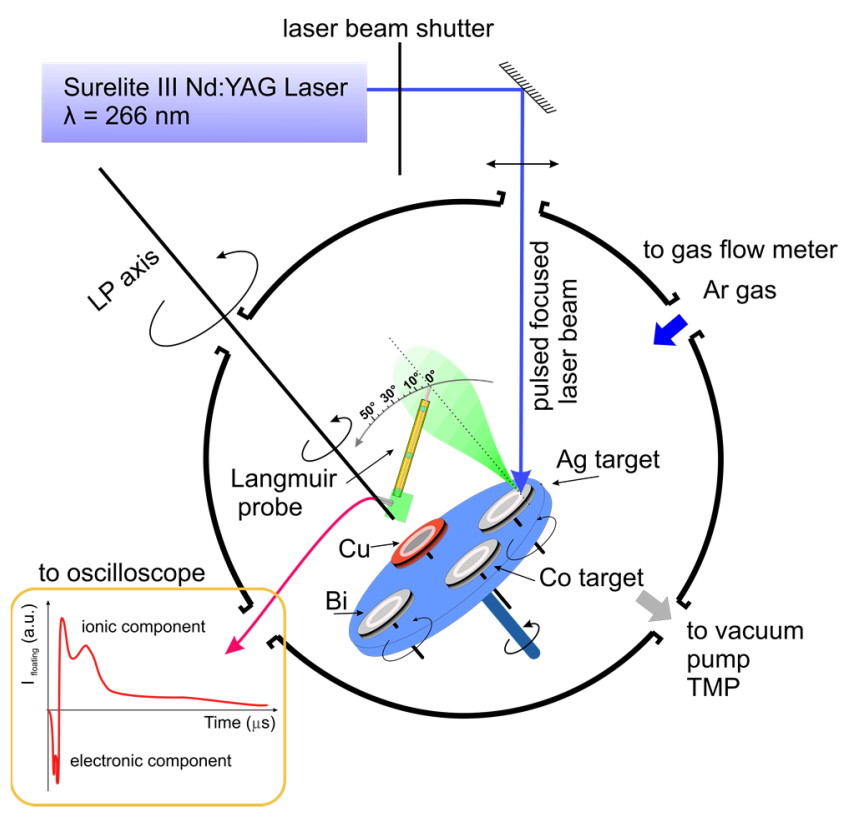

Figure 1. Experimental Set-up.

\section{Results and Discussions}

\section{Unbiased Probe Investigations of Metallic Plasmas}

In Figure $2 \mathrm{a}$ we have represented the unbiased probe signals recorded at $0^{\circ}$ (along the main target normal axis) of each investigated plasma in a free expansion regime. We observe that all the temporal traces have similar features: an electronic component for arrival times below 1-2 $\mu$ s and an ionic contribution for longer arrival times with specific characteristics to each material. The resulted ions can be directly ablated from the target, induced by single or multi-photon ionization processes, or generated through collisions in the early stages of ablation or by the plasma-working gas interactions. The dominant mechanisms are often dictated by the laser wavelength and fluence, target nature, or background gas pressure. Plasma generated in a vacuum on $\mathrm{Ag}$ or $\mathrm{Cu}$ has a clear three-peak structure (1st structure: $\mathrm{Ag}-22 \mathrm{~km} / \mathrm{s}, \mathrm{Cu}-28 \mathrm{~km} / \mathrm{s} ; 2$ nd structure $\mathrm{Ag}-8 \mathrm{~km} / \mathrm{s}, \mathrm{Cu}-12 \mathrm{~km} / \mathrm{s}, 3 \mathrm{rd}$ structure $\mathrm{Ag}-2 \mathrm{~km} / \mathrm{s}, \mathrm{Cu}-4 \mathrm{~km} / \mathrm{s})$. Each peak, according to our previous results [25] and from the model proposed by N. Bulgakova's group [29,30], corresponds to a different ionization state. For the case of $\mathrm{Cu}$, the three-peak structure in the ion density distribution has also been reported by S. Harilal's group [31] at higher laser fluences, with the difference in fluence being explained by the use of saturation current as the main investigation instrument. For the $\mathrm{Co}$ and $\mathrm{Bi}$, the plasma structuring is not obvious. This change can be interpreted to be induced by the differences in the properties of the irradiated target. Based on our previous work from [32] we showed that in the fs, ps and ns regimes the acceleration field can be correlated with the electrical conductivity of the target through the density of available electrons to be removed during the ablation process. Therefore, we can extend the same paradigm here and correlate the degree of structuring with the target's electrical conductivity as the strengths of the acceleration potential will be reflected in the expansion velocities of ionized species [26,29]. For all investigated plasma the electronic and ionic peaks shift towards lower arrival times as the atomic mass of the irradiated target decreases. This result confirms the interpretation of the LP temporal traces with a Coulomb-shifted Maxwell Boltzmann distribution where different contributions to the particle velocity (thermal, Coulomb and adiabatic) have a $\sqrt{1 / \mathrm{m}}$ type contribution [33]. 


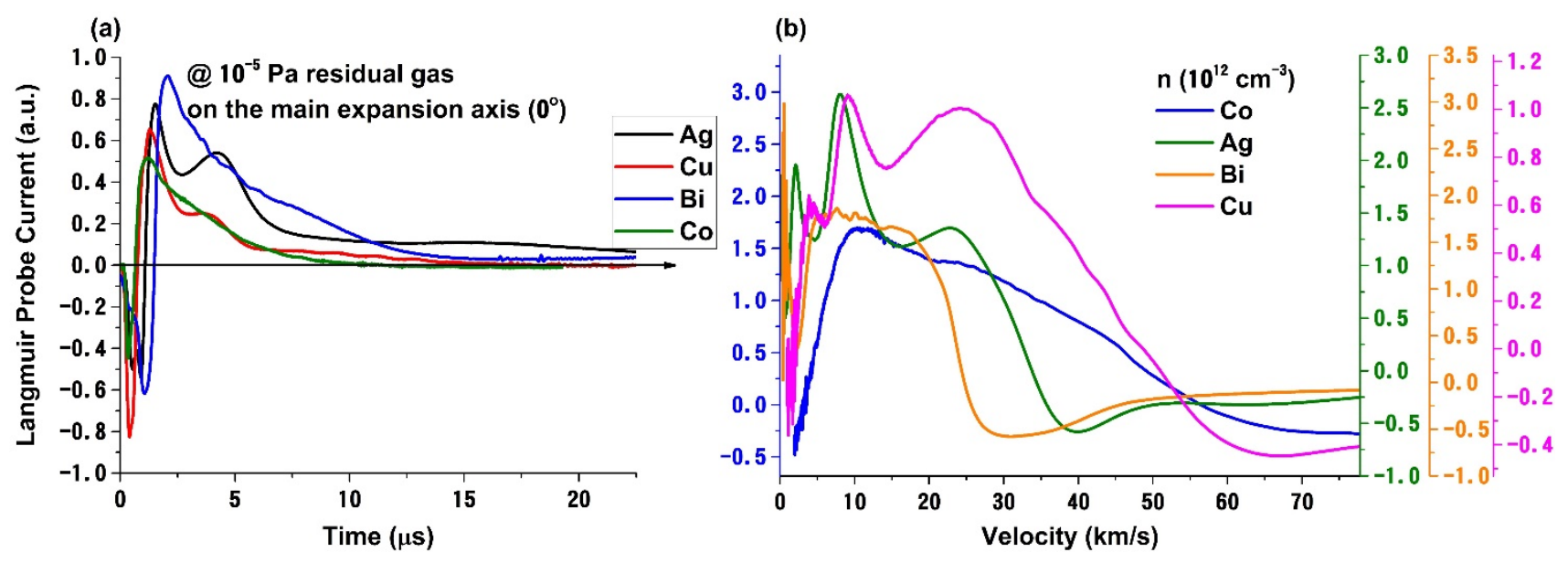

Figure 2. Un-biased probe current for several metallic plasmas (a) and the corresponding charge density distribution with expansion velocities $(\mathbf{b})$.

Using the procedure from [21] we reconstructed the charge density as a function of particle expansion velocity. We observe that in a high vacuum the structuring of the plasma is well in line with the previous data. Bi plasma is characterized by a narrow range of velocities of the ion structures (1st structure $-21 \mathrm{~km} / \mathrm{s}$, 2nd structure- $8 \mathrm{~km} / \mathrm{s}$, $3 \mathrm{rd}$ structure $-1.5 \mathrm{~km} / \mathrm{s}$ ) and a dominant peak around $1-2 \mathrm{~km} / \mathrm{s}$ which, according to the work of $[4,34,35]$ can be correlated with a nanoparticle (NP) dominated structure. We have confirmed the nature of this slow structure in a recent paper [24] where we investigated the deposition of Ag nanoparticles by PLD. The widest distribution with ions having velocities up to $60 \mathrm{~km} / \mathrm{s}$ is the Co plasma defined by low atomic mass particles which can gain more kinetic energy during the acceleration in the initial stages of ablation.

With such complex distributions seen for all investigated plasmas with multiple maxima and possible NP-induced structures, the control of plasma energy during the deposition becomes essential. Several routes for controlling the plasma kinetics are proposed in the literature including but not limited to fluence reduction [2,36], background gas addition [22,37,38], off-axis deposition [39], etc. The control from laser fluence can be challenging as changes in the transferred energy towards the target strongly affects the fundamental ablation mechanisms and often leads to the formation of clusters and droplets on the deposited film [40,41], which is undesirable. Therefore, in the following, we will only focus on the latter two approaches. The addition of Ar as an inert gas up to $10 \mathrm{~Pa}$ will lead to an energy transfer from the plasma plume towards the gas particles via collisions.

In Figure $3 a, b$ we plotted the ion particle velocity distributions at various Ar gas pressures. For the case of $\mathrm{Cu}$ plasma, the wide distribution seen in high vacuum conditions is confined towards lower velocity ranges from $28 \mathrm{~km} / \mathrm{s}$ for the first structure to $3 \mathrm{~km} / \mathrm{s}$, from $12 \mathrm{~km} / \mathrm{s}$ for the second structure to $1.3 \mathrm{~km} / \mathrm{s}$ and from $4 \mathrm{~km} / \mathrm{s}$ for the third structure to $0.2 \mathrm{~km} / \mathrm{s}$. For the case of Ag plasma, the plasma velocities extracted from charged particle distribution vary from $24 \mathrm{~km} / \mathrm{s}$ for the 1 st structure to $2 \mathrm{~km} / \mathrm{s}$, from $11.8 \mathrm{~km} / \mathrm{s}$ for the 2 nd structure to $3.5 \mathrm{~km} / \mathrm{s}$ and from $3 \mathrm{~km} / \mathrm{s}$ for the $3 \mathrm{rd}$ structure to $0.15 \mathrm{~km} / \mathrm{s}$. For the case of $\mathrm{Bi}$, we can see variations from $21 \mathrm{~km} / \mathrm{s}$ down to $1.3 \mathrm{~km} / \mathrm{s}$ for the 1 st structure, for the 2 nd one from $8 \mathrm{~km} / \mathrm{s}$ to $0.7 \mathrm{~km} / \mathrm{s}$ and lastly for the 3 rd one from $1.5 \mathrm{~km} / \mathrm{s}$ to $0.08 \mathrm{~km} / \mathrm{s}$. Finally, for the case of Co plasma, the particle velocity distribution seen in high vacuum conditions is confined from $42 \mathrm{~km} / \mathrm{s}$ for the first structure to $16.8 \mathrm{~km} / \mathrm{s}$, from $25 \mathrm{~km} / \mathrm{s}$ for the second structure to $0.66 \mathrm{~km} / \mathrm{s}$ and from $10 \mathrm{~km} / \mathrm{s}$ for the third structure to $0.14 \mathrm{~km} / \mathrm{s}$. These values are roughly in line with the results from [42] where are reported usual ranges for particle velocities for higher laser fluence conditions. The group of Anoop et al. [43] using a wide range of fluences and a shorter pulse width reported tens of $\mathrm{km} / \mathrm{s}$ for the ions and the front of the plasma and a few $\mathrm{km} / \mathrm{s}$ for the slower plasma structure dominated by atoms. Mahoney et al. [44] under similar conditions of laser wavelength and fluence 
reported velocities of $10-20 \mathrm{~km} / \mathrm{s}$ for the expanding plasma with a considerable reduction when adding $\mathrm{O}_{2}$ in the chamber.

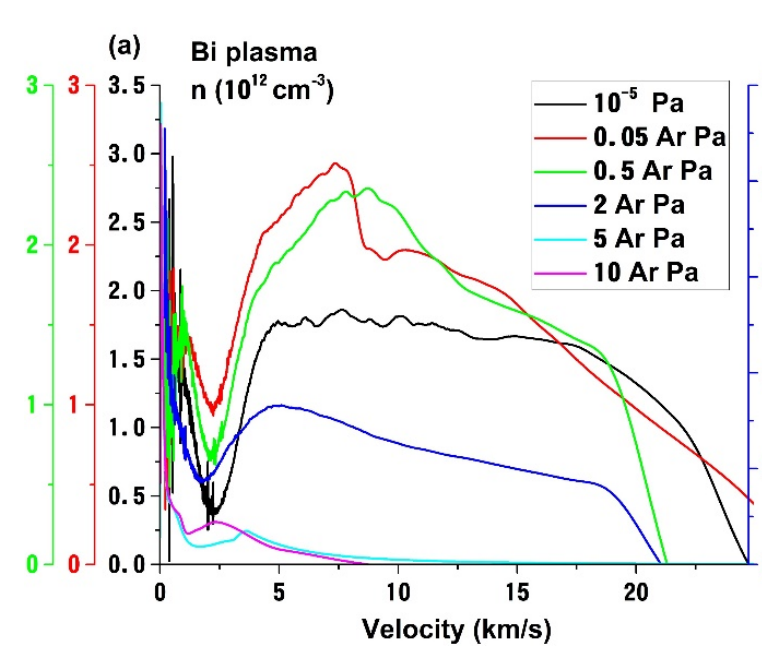

Bi plasma

(c) Expansion velocites ( $\mathrm{km} / \mathrm{s})$

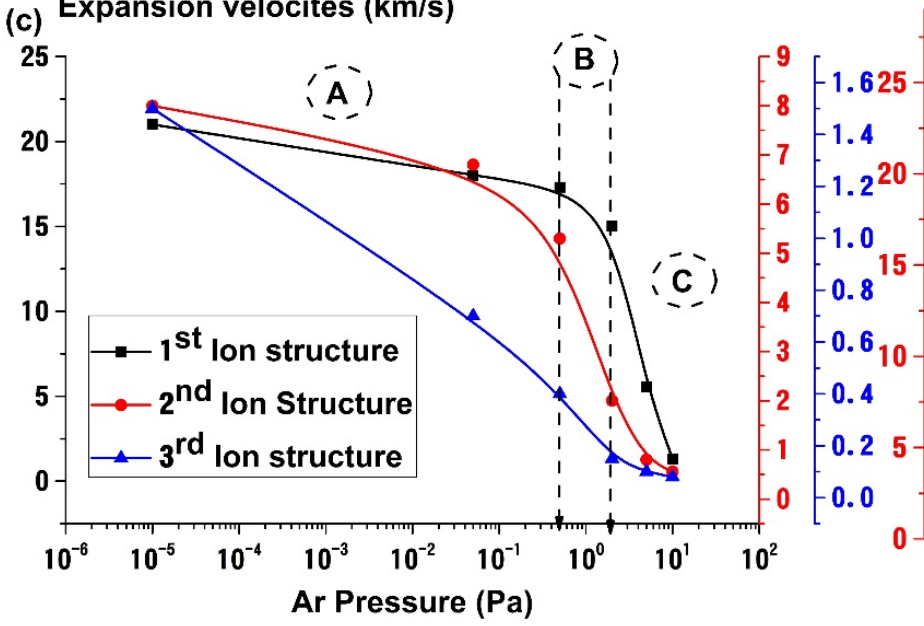

(d) Expansion velocites $(\mathrm{km} / \mathrm{s})$

(b) Co plasma
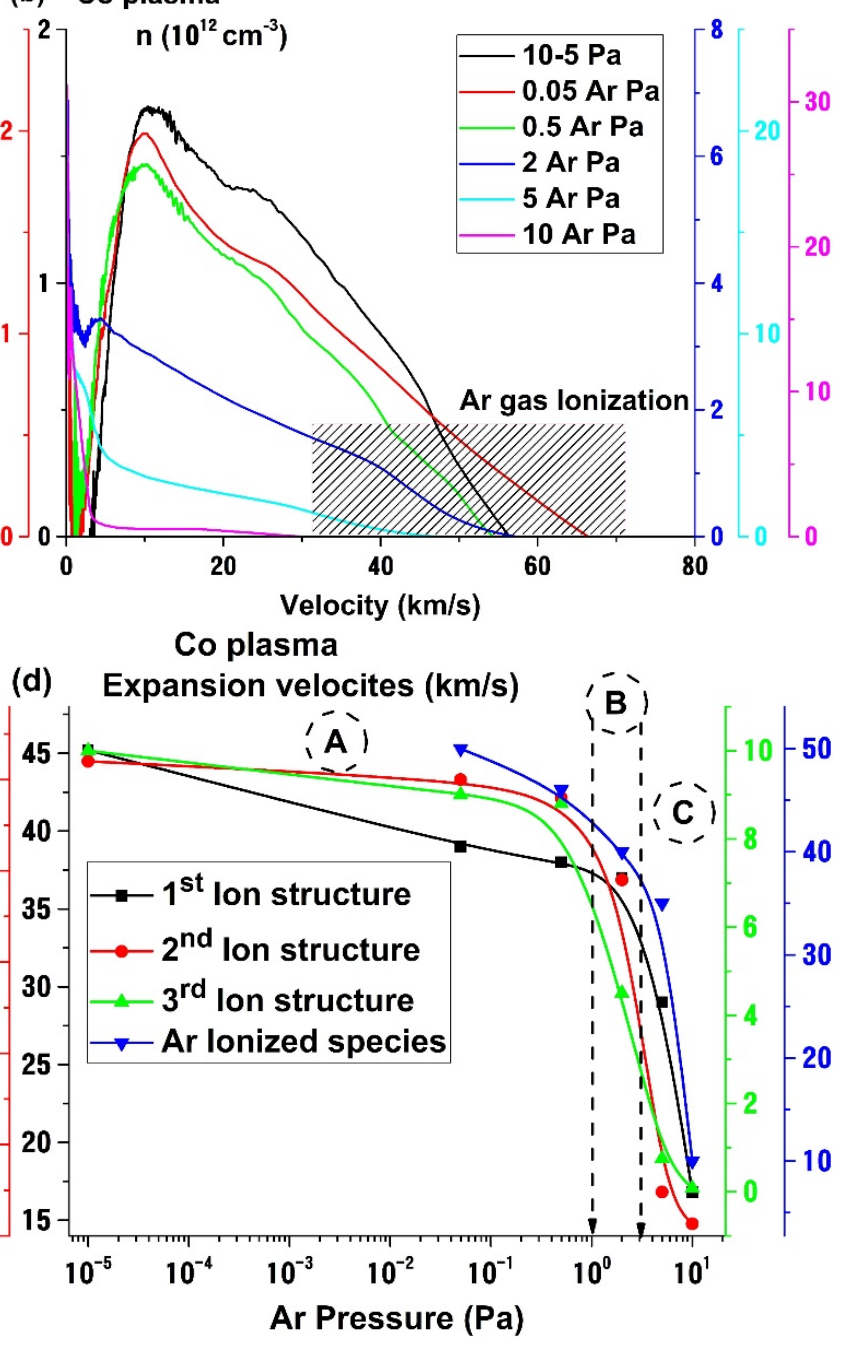

Ar Pressure (Pa) distribution characterizing the plasma expansion at $10^{-5} \mathrm{~Pa}$.

In Figure 3c,d we have represented the Ar pressure effect on the expansion velocity of each structure. For the case of $\mathrm{Bi}$, the three-structure seen in high vacuum evolves into a twostructure configuration (from $0.05 \mathrm{~Pa}$ ) with the two ionic groups with the slowest velocities merging together. For the case of $\mathrm{Co}$ (presented here) and for $\mathrm{Ag}$ and $\mathrm{Cu}$ (not shown) we observe all the three expansion regimes. The $A$ region characterizes the free expansion regime where only collisions occur within the plasma volume and the expansion velocities suffer a decrease of approximately $10 \%$ up to $0.5 \mathrm{~Pa}$. This pressure value represents the threshold $(B)$ which signals the transition from free expansion towards a collision-driven regime (C), for which we see a steep drop of $30 \%$. The velocities attributed to the ionized Ar plasma (blue curve in Figure 3d) are of tens of $\mathrm{km} / \mathrm{s}$ range and close to the values of the fastest ion group which confirms their origin. The ionized Ar is generated only at the front (edges) of the plume where the electrons and fast ions have enough energy to ionize and excite the $\mathrm{Ar}$ gas atoms. For many metallic plasmas $(\mathrm{Cu}, \mathrm{Ag}, \mathrm{Co})$ the most probable velocities of the electrons are in the hundreds of $\mathrm{km} / \mathrm{s}$ range. The resulting kinetic energies for the front of the plasma would be around $500 \mathrm{eV}$ in the case of $\mathrm{Co}, 270 \mathrm{eV}$ for $\mathrm{Cu}$, to $260 \mathrm{eV}$ for $\mathrm{Ag}$ and $200 \mathrm{eV}$ for $\mathrm{Bi}$. These values considerably surpass the ionization 
potential of $\mathrm{Ar}(15.3 \mathrm{eV})$. From $0.5 \mathrm{~Pa}$ Ar pressure the mean free path decreases from $1.3 \mathrm{~cm}$ to $6.5 \times 10^{-2} \mathrm{~cm}$ at $10 \mathrm{~Pa}$, thus the appearance of a new peak is correlated with Ar gas ionization during expansion. For the case of $\mathrm{Bi}$, the ejected charge energy coupled with the wider angular distribution led to fewer Ar gas ionization, as no new peak was detected in Bi particle velocity distribution.

We recently showed by using optical emission spectroscopy that Ag plasma can ionize Ar gas during the deposition of Ag NP and influence the structural quality and surface morphology of the films. Regarding the background gas, Isaac et al. [45] have even reported the full ionization of $27 \mathrm{~Pa}$ of Ar gas in the vicinity $(0.6-1 \mathrm{~mm})$ of the Ag target by means of OES investigations while Amoruso et al. [46], when investigating the laser ablation of $\mathrm{MgB}_{2}$ in $10 \mathrm{~Pa}$ of Ar gas reported similar conclusions.

To better understand the charged particle distributions, we performed a deconvolution of the measured traces. Selected data on Co and Bi plasma expanding in $10^{-5} \mathrm{~Pa}$ are presented in Figure $4 \mathrm{a}, \mathrm{b}$. The general laws describing the particle distribution in laser produced plasmas are defined, as reported in $[47,48]$, through Coulomb shifted Maxwell Boltzmann distributions. The fitting procedure follows the separation between the plasma structures, with three peaks characterized by high velocities and the NP structure, which is defined by a low expansion velocity. Our analysis also showed that the NP structure has the largest FWHM compared to any other plasma structure. In the case of $\mathrm{Bi}$, we found $5.9 \mathrm{~km} / \mathrm{s}$ for NP while for the three plasma structures we found $\mathrm{Ag}-5 \mathrm{~km} / \mathrm{s}, \mathrm{Cu}-4.5 \mathrm{~km} / \mathrm{s}$ and $\mathrm{Co}-4 \mathrm{~km} / \mathrm{s}$, respectively. The presence of high energetic groups of ions within the plasma when relating the data to pulsed laser deposition raises the question of re-sputtering of the deposited film. For the second and third structures in vacuum conditions, the kinetic energies of the investigated plasmas are $\mathrm{Co} 2 \mathrm{nd}-185 \mathrm{eV}, \mathrm{Cu} 2 \mathrm{nd}-50 \mathrm{eV}$. Ag 2nd-35 eV. Bi 2nd-16 eV. and Co 3rd-185 eV, Cu 3rd-50 eV. Ag 3rd-35 eV. Bi 3rd-16 eV. This means that there is a strong possibility in vacuum conditions for re-sputtering to be a key phenomenon during the deposition process, as the bonding energy of the deposited metals are considerably lower (Ag: $1.68 \mathrm{eV}$; Co: $1.31 \mathrm{eV}$; $\mathrm{Cu}: 2.08 \mathrm{eV}$; Bi: $2.11 \mathrm{eV}$ ). The situation changes from $0.5 \mathrm{~Pa}$ upwards, when the kinetic energies are decreasing enough to avoid the appearance of re-sputtering; under these conditions, the deposition/growth rate of the film should increase significantly. This is confirmed experimentally as it was previously reported in $[44,49]$, but there wasn't given a quantifiable set of data that can be transferable to other deposition conditions as is given here.
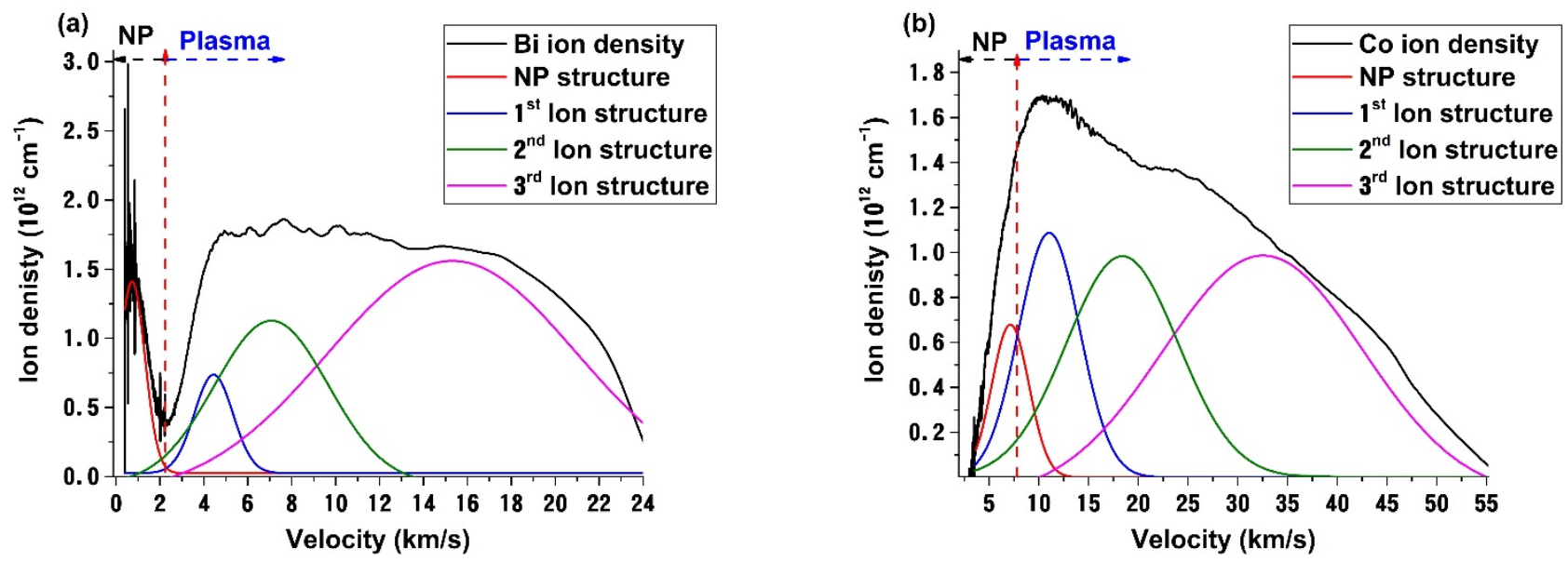

Figure 4. Deconvolution of the charge density velocity distribution of $\mathrm{Bi}(\mathbf{a})$ and $\mathrm{Co}(\mathbf{b})$ plasmas for the $10^{-5} \mathrm{~Pa}$ case.

As laser produced plasmas present a strong angular distribution of their properties it is important to see how these properties can potentially affect the deposition process. For all the investigated metals and based on the previously available data, most plasmas have a

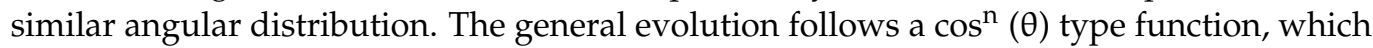


was shown for a wide range of the particle-based on saturation current measurements and thin quartz crystal microbalance or thin-film thickness measurements [50,51]. In one of our previous works, we showed, based on their energy, that not all plasma species follow the same angular trend, with low energy particles presenting a strong shoulder towards higher angles. The latter was found here for Bi plasma which has particles with higher kinetic energies towards the edges of the plasma, as opposed to Co, $\mathrm{Ag}$, and $\mathrm{Cu}$, which have an energetic maximum in the center of the plasma plume. Similar results were reported in $[17,52]$ where a strong angular heterogeneity based on the mass of the ablated particles seen through optical emission spectroscopy and mass spectrometry measurements was observed. From the selected metals investigated here (seen in Figure 5), Ag and Cu plasmas have a strong angular gradient with velocities decreasing from $24 \mathrm{~km} / \mathrm{s}$ at $0^{\circ}$ to $2 \mathrm{~km} / \mathrm{s}$ at $50^{\circ}$ for $\mathrm{Ag}$ and $28 \mathrm{~km} / \mathrm{s}$ at $0^{\circ}$ to $8 \mathrm{~km} / \mathrm{s}$ at $50^{\circ}$ for $\mathrm{Cu}$. The shift of the distribution towards low energies is seen also for electron-dominated structures which are accompanied by a steep decrease in electron density of $90 \%$ for $\mathrm{Ag}$ and $42 \%$ for Cu. A special case is seen for Co plasma where a negative peak in the distribution is characterizing low energy particles. Based on their velocity and the data reported in [52], the peak should correspond to positively charged particles. The position of the maximum does not vary, remaining centered around $2 \mathrm{~km} / \mathrm{s}$, however, its amplitude increases with about one order of magnitude from $3.4 \times 10^{11}$ to $3.4 \times 10^{12}$ when the measuring angle is varied from $0^{\circ}$ to $50^{\circ}$. Based on this behavior we can conclude that this slow structure is not affected by the initial acceleration of the ejected charges, signaling a longer incubation time for their ejection. The variation in intensity would be correlated with the energy distribution of the laser beam at the irradiated surface and suggests a thermal mechanism for ejection (explosive boiling or thermal evaporation). Similar behavior is also seen for $\mathrm{Bi}$, where the initial peak identified as NP in the previous section, changes its charge towards the edge of the plasma. Additionally, the area highlighted in Figure $4 \mathrm{~d}$ represents a secondary contribution of the positive Bi ions for wide measuring angles from $30^{\circ}$ to $50^{\circ}$. The presence of metal anions in laser-produced plasmas has only been reported by the use of time-of-flight mass spectrometry measurements [53-56]; this is one of the first attempts to extend the LP probe technique towards understanding positive ion dynamics during the deposition process.
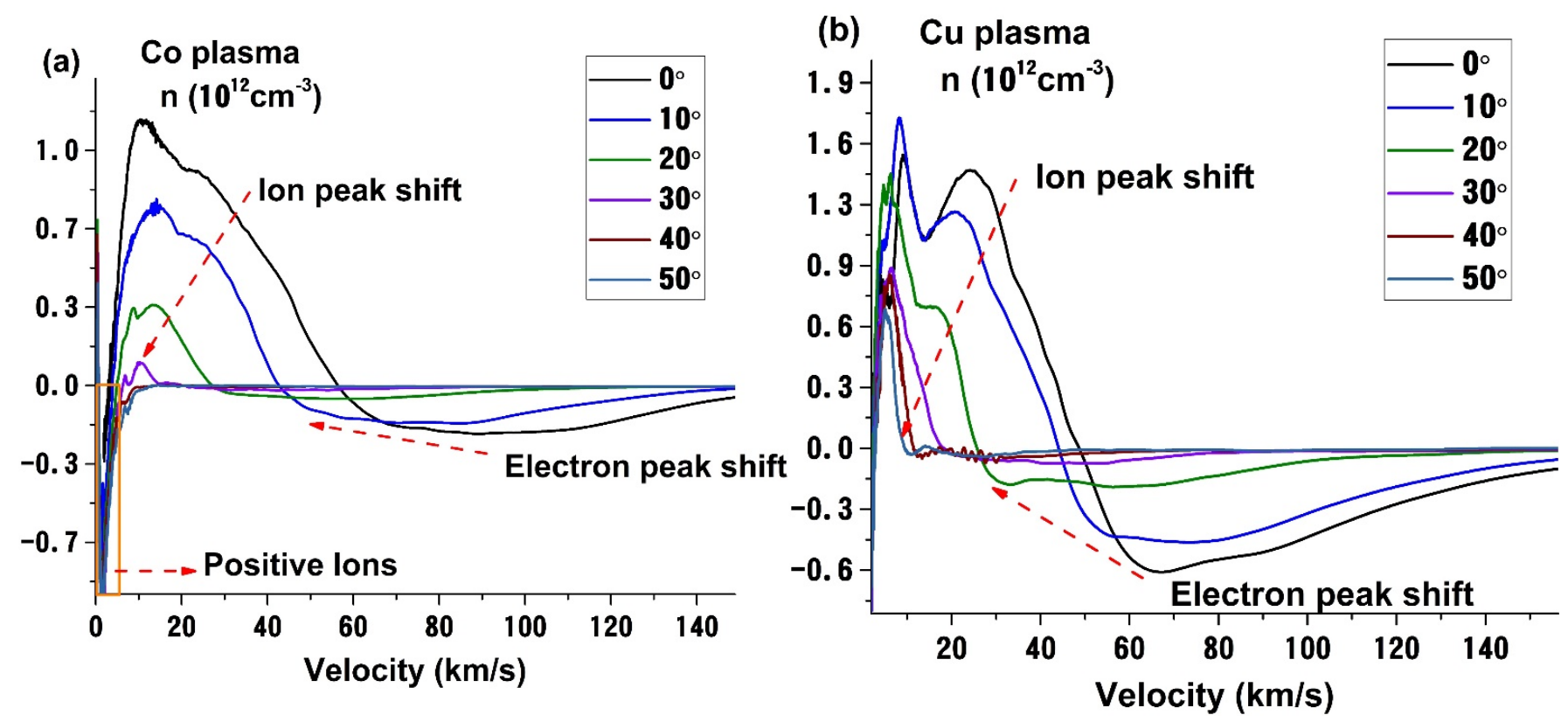

Figure 5. Cont. 

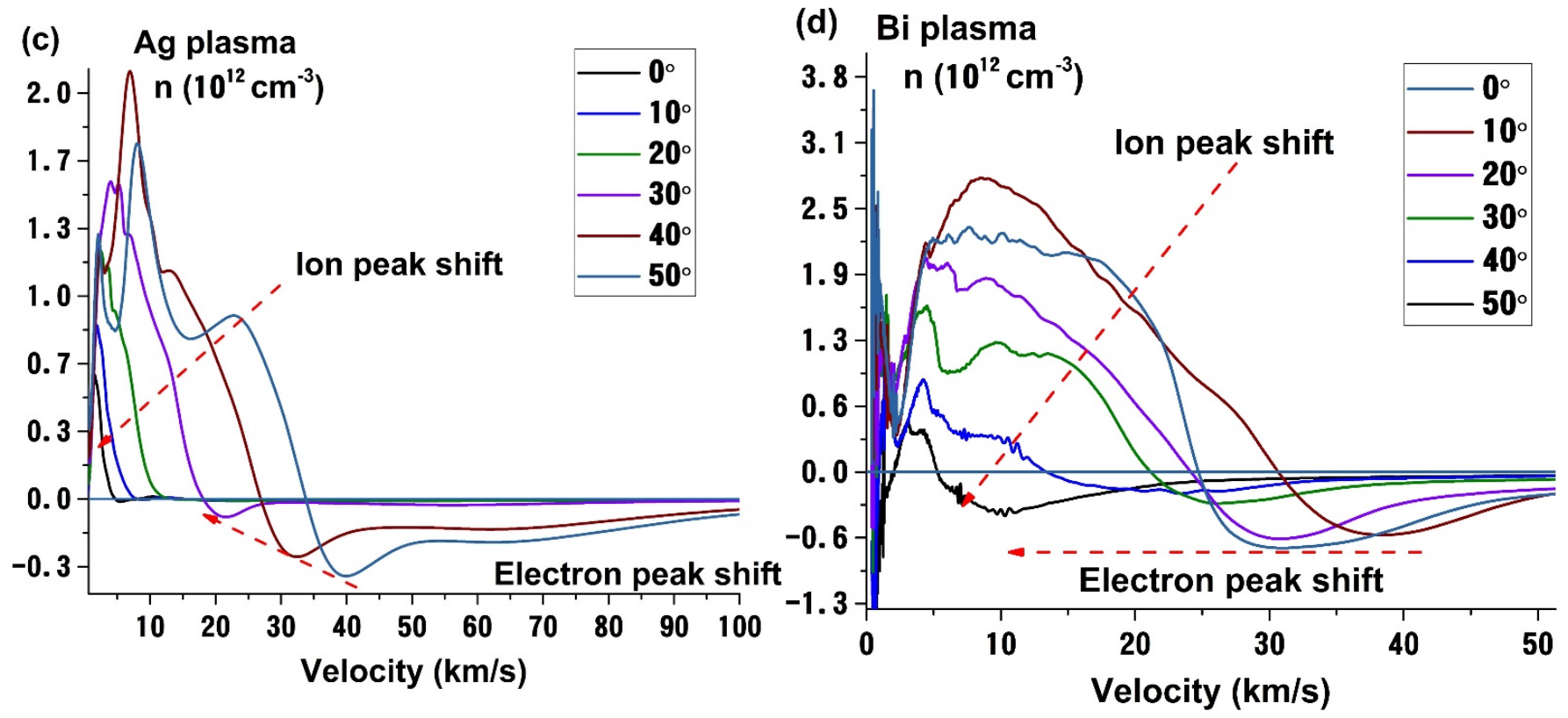

Figure 5. Angular dependence of charged particle velocity distribution for the investigated metallic plasmas (Co (a); Cu (b); $\operatorname{Ag}(\mathbf{c}) ; \operatorname{Bi}(\mathbf{d}))$.

\section{Target Properties Influence on Plasma Dynamics}

Finally, let us focus on the possible relation between the properties of the targets and the ones of the plasma. Our approach only considers the unbiased probe current as a true measure of the charge density dynamics. This puts us in an advantageous position as we can analyze in one step various ionic and electronic plasma structures, including, as we have shown, NP and positive ions. Some relations were found between the melting temperature, atomic mass, target's electric conductivity and plasma parameters like expansion velocity, ion density, or electron temperature. The data are presented in Figure 6. We observe that the velocities of the ejected ions have a clear dependence on the atomic mass, thus confirming the nature of the measured velocity is of Coulomb nature and given by the relation [57] $\sqrt{\frac{2 z e V_{0}}{m}}$, with $z$-the charge state, $e$ - the electron charge and $V_{0}$-the accelerated voltage formed at the edges of the double layer formed during expansion.

Additionally, the velocity is seen to have a quasi-exponential increase as a function of the melting temperature. With the increase of the melting temperature the vaporization and overall thermal ablation mechanism are hindered with the laser energy being transferred towards electrostatic ablation and charged particle acceleration. The electron temperature, determined using the procedure from [21], increases with the increase of target conductivity, which confirms the results from [26] where different sets of metals were investigated. The temperature increases as a result of the change in the electrostatic/thermal mechanism balance occurring in the initial stages of ablation which leads to an enhancing of the electron thermal movement within the plasma plume. Although, here we don't have the same function describing the $\sigma\left(\mathrm{T}_{\mathrm{e}}\right)$ function as previously reported on [32] we still find a proportionality between the two parameters. This is explained by the larger measurement distance used here and the smaller range of investigated materials. Finally, when representing the charged particle density as a function of the melting point of the investigated materials we found that they follow a decreasing trend. The latter dependence is sustained by reports [14,15] for ns laser produce plasma and confirmed also for shorter pulse lengths [58] where the decrease in target volatility defined by an increase of cohesion energy or melting temperature of the target will lead to the ejection of a lower particle density. These results concerning the plasma properties and their angular distribution for the selected metals will potentially impact the efficiency of metal nanoparticles production 
either for plasmonic or magnetic application for effective fabrication of magnetoplasmonic structures $[59,60]$.

(a)

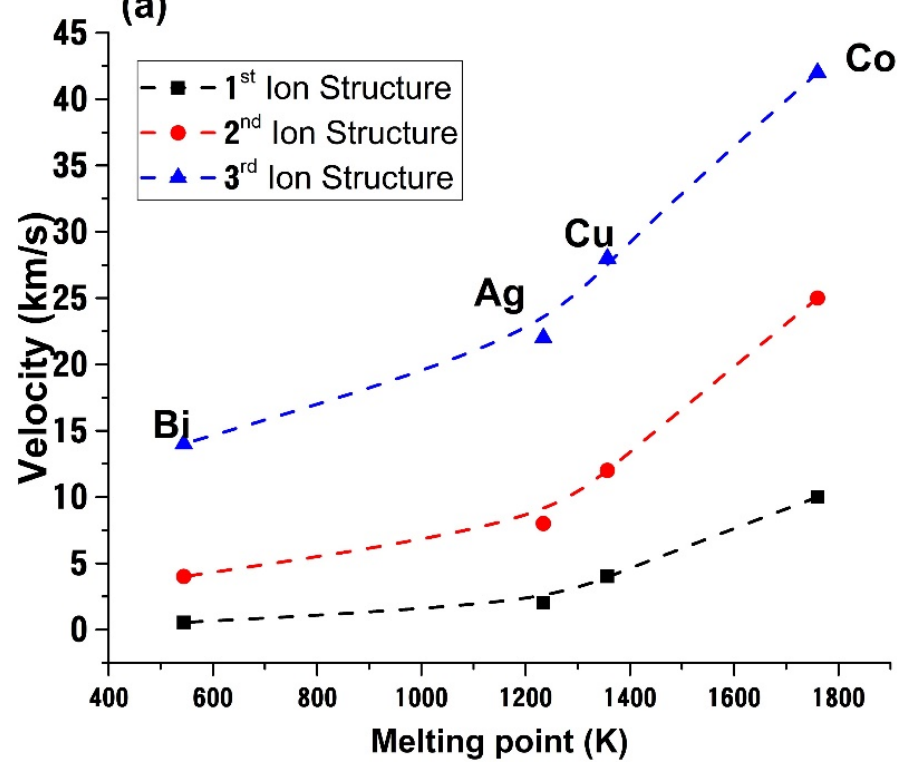

(c)

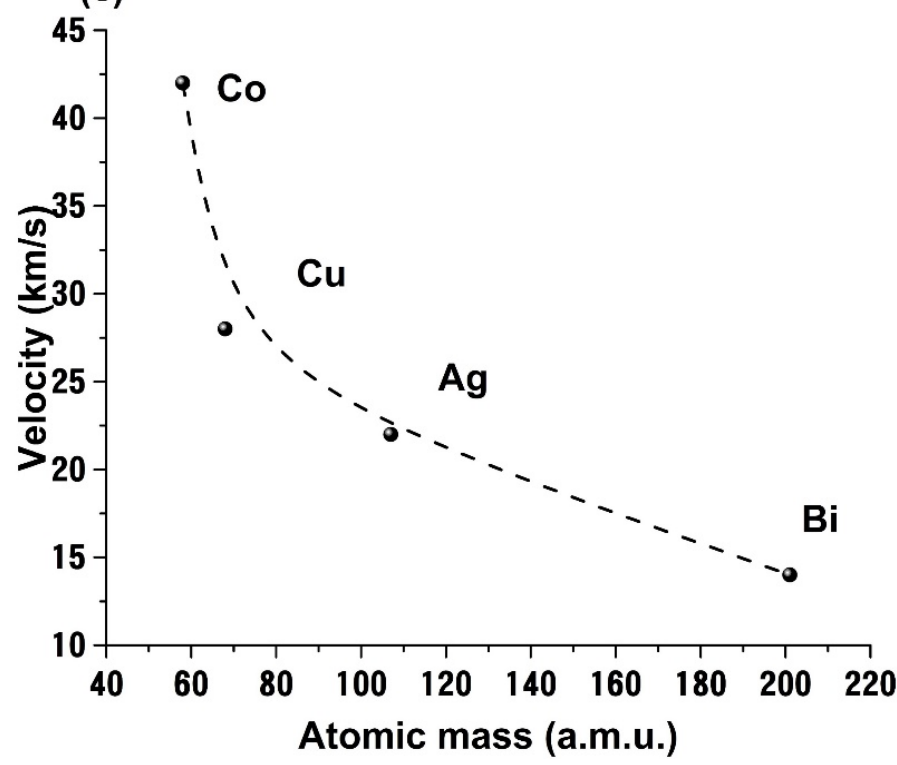

(b)

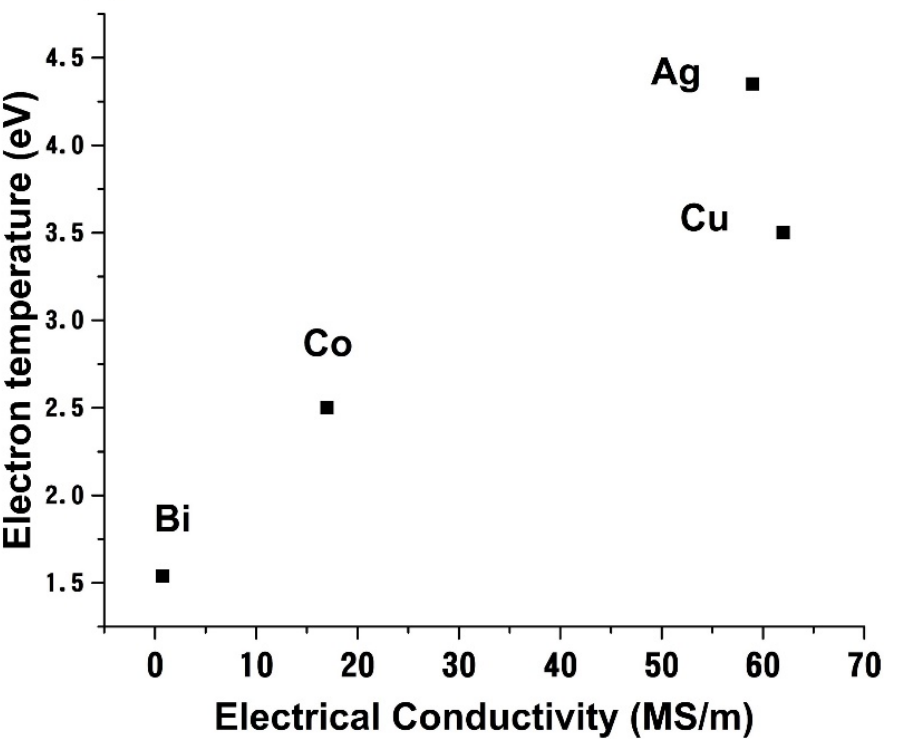

(d)

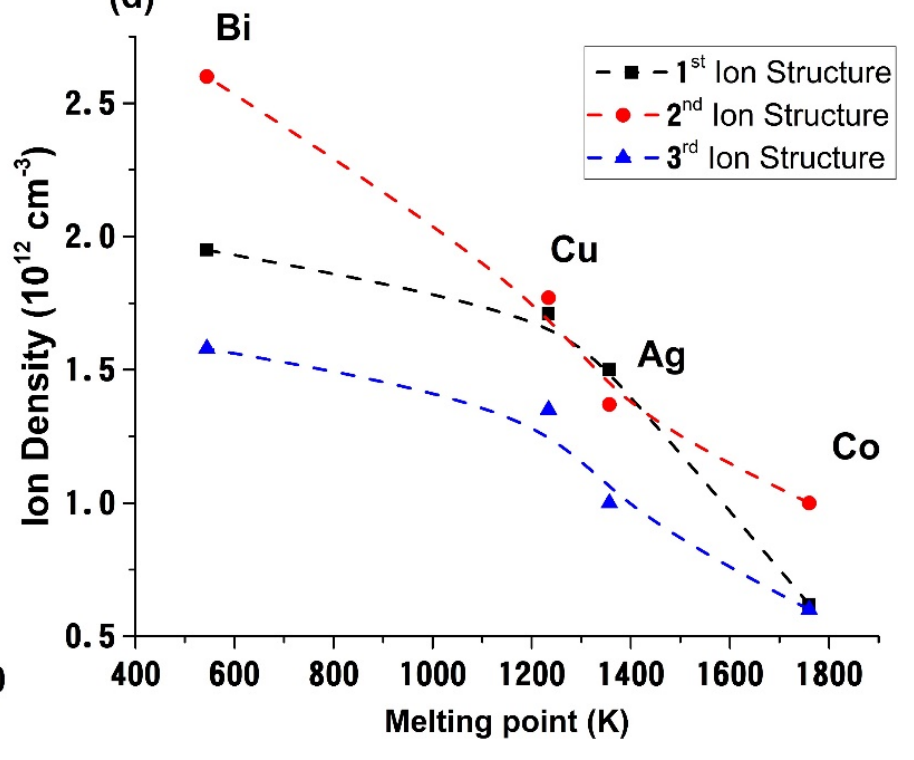

Figure 6. Dependence of expansion velocity on melting point (a), electron temperature on target electrical conductivity (b) expansion velocity on atomic mass (c) and ion density on melting point (d); lines are guide to the eye.

Although LP is limited to the measurement of charge structure from the plasma (particle, clusters, NP, etc.) by implementing a semi-empirical model [47] on the time-offlight data we can extract a series of parameters that characterize global parameters of the plasma-like, neutral temperature, average ionization state or acceleration field. Our data shows that the neutral densities generated through the ablation mechanism are lower than the ionic ones. The highest neutral density was found for Co: $6.1 \times 10^{10} \mathrm{~cm}^{-3}$ followed by Ag: $3.1 \times 10^{10} \mathrm{~cm}^{-3}$ and $\mathrm{Cu}: 1.6 \times 10^{10} \mathrm{~cm}^{-3}$ with the lowest values obtained for Bi: $2 \times 10^{8} \mathrm{~cm}^{-2}$. This result contradicts the LP data which shows higher densities being correlated with the melting point of the sample. To understand this difference, it is important to take into account the NP formation and/or direct ejection from the sample and to consider the difference of about 2 orders of magnitude between $\mathrm{Ag}, \mathrm{Cu}, \mathrm{Co}$ and $\mathrm{Bi}$. 
These calculations show that although the plasma respects the dependence of the target's volatility, the neutral core of the plasma could lose an important percentage towards NP or clusters formation, results confirmed from angle resolved LP where we saw important NP contribution of $\mathrm{Bi}$ as opposed to $\mathrm{Ag}$ or $\mathrm{Cu}$. The average ionization states were calculated and we found that $\mathrm{Cu}$ (4) and $\mathrm{Ag}$ (3.5) have higher ionization states, while $\mathrm{Bi}(0.9)$ and $\mathrm{Co}$ (2) were on the other end of the distribution. We noticed that these differences are well correlated with the differences seen in the acceleration field (ex: $\mathrm{Cu}: 4.6 \mathrm{MV} / \mathrm{cm}$ and Bi: $0.5 \mathrm{MV} / \mathrm{cm}$ ) and are causing the difference in expansion velocities between the investigated plasmas and the structuring of the charged particle velocity distribution.

\section{Conclusions}

Extensive investigations based on angle and time-resolved unbiased Langmuir probe measurements were performed on a series of metals relevant to nanoparticles production via pulsed laser deposition. The measurements on the main expansion axis revealed a complex structuring of the electronic and ionic contributions to the probe current. The degree of plasma structuring was correlated with the average ionization states and the acceleration field generated in the incipient moments of ablation. The addition of Ar gas led to the confinement of the plasma towards lower expansion velocities and the increase by several orders of magnitude in ion density. Above $0.5 \mathrm{~Pa}$ Ar pressure, the generation of a new, faster ionic structure is seen and was attributed to the ionization of Ar gas during expansion. The balance between the energy of the plasma structure and the Ar ionization process sustains the proposed hypothesis. For the case of softer materials (Bi), we saw that a supplementary plasma structure, attributed to the formation of metallic nanoparticles from the gas phase, is visible from $10^{-5} \mathrm{~Pa}$. The formation of a higher density of NP was reflected in the drop of neutral particle density by several orders of magnitude. Several correlations were made between the target -plasma properties. The expansion velocity was seen increasing with the increase of melting points and decreasing with the atomic mass, revealing a dominance of the electrostatic mechanism in charged particles acceleration. The charged particles density was found to decrease with the increase of the melting point, anchoring the relationship between the volatility of the sample and the overall abated mass.

Author Contributions: Conceptualization, V.C., S.A.I. and J.L.; methodology, S.A.I. and S.C.; validation, S.A.I., S.C., V.C., M.N. and J.L.; investigation, S.A.I. and S.C.; resources, J.L., M.N. and V.C.; writing-original draft preparation, S.A.I., S.C., V.C., M.N. and J.L.; writing-review and editing, S.A.I., S.C., V.C., M.N. and J.L.; visualization, S.A.I. and S.C.; supervision, J.L. and V.C.; project administration, J.L. and V.C.; funding acquisition, J.L., V.C. and S.A.I. All authors have read and agreed to the published version of the manuscript.

Funding: This work was supported by the Czech Science Foundation (GAČR) under project No. 20-21069S and by the Romanian Ministry of Education and Research under the Romanian National Nuclear Program LAPLAS VI (contract n. 16N/2019, ELI-RO_2020_12) and Postdoctoral Project PD 145/2020. We acknowledge the Operational Program Research, Development and Education financed by European Structural and Investment Funds and the Czech Ministry of Education, Youth and Sports (SOLID21 CZ.02.1.01/0.0/0.0/16_019/0000760).

Institutional Review Board Statement: Not applicable.

Informed Consent Statement: Not applicable.

Data Availability Statement: The data that support the findings of this study are available from the corresponding author upon reasonable request.

Conflicts of Interest: The authors declare no conflict of interest.

\section{References}

1. Vakulov, Z.; Khakhulin, D.; Zamburg, E.; Mikhaylichenko, A.; Smirnov, V.A.; Tominov, R.; Klimin, V.S.; Ageev, O.A. Towards scalable large-area pulsed laser deposition. Materials 2021, 14, 4854. [CrossRef]

2. Pan, S.; Li, Q.; Xian, Z.; Su, N.; Zeng, F. The effects of laser parameters and the ablation mechanism in laser ablation of c/sic composite. Materials 2019, 12, 3076. [CrossRef] 
3. Santillán, J.M.J.; Muñetón Arboleda, D.; Muraca, D.; Schinca, D.C.; Scaffardi, L.B. Highly fluorescent few atoms silver nanoclusters with strong photocatalytic activity synthesized by ultrashort light pulses. Sci. Rep. 2020, 10, 8217. [CrossRef]

4. Barberio, M.; Antici, P. In situ study of nucleation and aggregation phases for nanoparticles grown by laser-driven methods. Sci. Rep. 2017, 7, 85-87.

5. Marcinkevičius, A.; Juodkazis, S.; Watanabe, M.; Miwa, M.; Matsuo, S.; Misawa, H.; Nishii, J. Femtosecond laser-assisted three-dimensional microfabrication in silica. Opt. Lett. 2001, 26, 277. [CrossRef] [PubMed]

6. Aguilera, J.A.; Aragón, C. Multi-element Saha-Boltzmann and Boltzmann plots in laser-induced plasmas. Spectrochim. Acta Part B At. Spectrosc. 2007, 62, 378-385. [CrossRef]

7. Hermann, J.; Axente, E.; Pelascini, F.; Craciun, V. Analysis of multi-elemental thin films via calibration-free laser-induced breakdown spectroscopy. Anal. Chem. 2019, 91, 2544-2550. [CrossRef] [PubMed]

8. Hermann, J.; Noël, S.; Itina, T.E.; Axente, E.; Povarnitsyn, M.E. Correlation between ablation efficiency and nanoparticle generation during the short-pulse laser ablation of metals. Laser Phys. 2008, 18, 374-379. [CrossRef]

9. Hermann, J.; Mercadier, L.; Axente, E.; Noël, S. Properties of plasmas produced by short double pulse laser ablation of metals. J. Phys. Conf. Ser. 2012, 399, 012006. [CrossRef]

10. Bykov, N.Y.; Bulgakova, N.M.; Bulgakov, A.V.; Loukianov, G.A. Pulsed laser ablation of metals in vacuum: DSMC study versus experiment. Appl. Phys. A Mater. Sci. Process. 2004, 79, 1097-1100. [CrossRef]

11. Lunney, J.G.; Jordan, R. Pulsed laser ablation of metals. Appl. Surf. Sci. 1998, 127-129, 941-946. [CrossRef]

12. Wood, R.F.; Chen, K.R.; Leboeuf, J.N.; Puretzky, A.A.; Geohegan, D.B. Dynamics of plume propagation and splitting during pulsed-laser ablation. Phys. Rev. Lett. 1997, 79, 1571-1574. [CrossRef]

13. Baraldi, G.; Pere, A.; Afonso, C.N. Dynamics of ions produced by laser ablation of several metals at $193 \mathrm{~nm}$. J. Appl. Phys. 2011, 109, 043302. [CrossRef]

14. Thestrup, B.; Toftmann, B.; Schou, J.; Doggett, B.; Lunney, J.G. Ion dynamics in laser ablation plumes from selected metals at 355 nm. Appl. Surf. Sci. 2002, 197-198, 175-180. [CrossRef]

15. Salle, B.; Chaleard, C.; Detalle, V.; Lacour, J.-L.; Mauchien, P.; Nouvellon, C.; Semerok, A. Laser ablation efficiency of metal samples with UV laser nanosecond pulses. Appl. Surf. Sci. 1999, 138-139, 302-305. [CrossRef]

16. Konomi, I.; Motohiro, T.; Asaoka, T. Angular distribution of atoms ejected by laser ablation of different metals. J. Appl. Phys. 2009, 106, 013107. [CrossRef]

17. Canulescu, S.; Papadopoulou, E.L.; Anglos, D.; Lippert, T.; Schneider, C.W.; Wokaun, A. Mechanisms of the laser plume expansion during the ablation of $\mathrm{LiMn}_{2} \mathrm{O}_{4}$. J. Appl. Phys. 2009, 105, 063107. [CrossRef]

18. Anoop, K.K.; Harilal, S.S.; Philip, R.; Bruzzese, R.; Amoruso, S. Laser fluence dependence on emission dynamics of ultrafast laser induced copper plasma. J. Appl. Phys. 2016, 120, 185901. [CrossRef]

19. Ni, K.; Anoop, K.K.; Bianco, M.; Amoruso, S.; Wang, X.; Li, T.; Hu, M.; Song, Z. Ion dynamics in ultrafast laser ablation of copper target. Chin. Opt. Lett. 2020, 11, 093201.

20. Tsakiris, N.; Anoop, K.K.; Ausanio, G.; Gill-Comeau, M.; Bruzzese, R.; Amoruso, S.; Lewis, L.J. Ultrashort laser ablation of bulk copper targets: Dynamics and size distribution of the generated nanoparticles. J. Appl. Phys. 2014, 115, 243301. [CrossRef]

21. Irimiciuc, S.A.; Chertopalov, S.; Lancok, J.; Craciun, V. Langmuir Probe technique for plasma characterization during pulsed laser Deposition process. Coatings 2021, 11, 762. [CrossRef]

22. Irimiciuc, S.A.; Hodoroaba, B.C.; Bulai, G.; Gurlui, S.; Craciun, V. Multiple structure formation and molecule dynamics in transient plasmas generated by laser ablation of graphite. Spectrochim. Acta Part B At. Spectrosc. 2020, 165, 105774. [CrossRef]

23. IrimiciucNovonty, M.; Fitl, P.; Bulir, J.; More-Chevalier, J.; Fekete, L.; Hruska, P.; Chertopalov, S.; Vrnata, M.; Lancok, J. In situ monitoring of electrical resistivity and plasma during pulsed laser deposition growth of ultra-thin silver films. J. Appl. Phys. 2021, $130,085301$.

24. Irimiciuc, S.A.; Chertopalov, S.; Bulíř, J.; Fekete, L.; Vondráček, M.; Novotný, M.; Craciun, V.; Lancok, J. In situ optical and electrical analysis of transient plasmas generated by ns-laser ablation for Ag nanostructured film production. Vacuum 2021, 193, 110528. [CrossRef]

25. Irimiciuc, S.A.; Chertopalov, S.; Craciun, V.; Novotný, M.; Lancok, J. Investigation of laser-produced plasma multistructuring by floating probe measurements and optical emission spectroscopy. Plasma Process. Polym. 2020, 17, 2000136. [CrossRef]

26. Irimiciuc, S.A.; Gurlui, S.; Bulai, G.; Nica, P.; Agop, M.; Focsa, C. Langmuir probe investigation of transient plasmas generated by femtosecond laser ablation of several metals: Influence of the target physical properties on the plume dynamics. Appl. Surf. Sci. 2017, 417, 108-118. [CrossRef]

27. Hansen, T.N.; Schou, J.; Lunney, J.G. Ion time-of-flight study of laser ablation of silver in low pressure gases. Appl. Surf. Sci. 1999, 138-139, 184-187. [CrossRef]

28. Irimiciuc, S.A.; Chertopalov, S.; Bulir, J.; Vondracek, M.; Fekete, L.; Jiricek, P.; Novotny, M.; Craciun, V.; Lancok, J. Insight into the plasma oxidation process during pulsed laser deposition. Plasma Process. Polym. 2021, 17, e2100102. [CrossRef]

29. Ojeda-G-P, A.; Yao, X.; Bulgakova, N.M.; Bulgakov, A.V.; Lippert, T. A dynamic double layer as the origin of the mass-dependent ion acceleration in laser-induced plasmas. Appl. Phys. A Mater. Sci. Process. 2019, 125, 71.

30. Marine, W.; Bulgakova, N.M.N.M.; Patrone, L.; Ozerov, I. Electronic mechanism of ion expulsion under UV nanosecond laser excitation of silicon: Experiment and modeling. Appl. Phys. A 2004, 79, 771-774. [CrossRef] 
31. Verhoff, B.; Harilal, S.S.; Freeman, J.R.; Diwakar, P.K.; Hassanein, A. Dynamics of femto- and nanosecond laser ablation plumes investigated using optical emission spectroscopy. J. Appl. Phys. 2012, 112, 093303. [CrossRef]

32. Irimiciuc, S.A.; Nica, P.E.; Agop, M.; Focsa, C. Target properties-Plasma dynamics relationship in laser ablation of metals: Common trends for fs, ps and ns irradiation regimes. Appl. Surf. Sci. 2020, 506, 144926. [CrossRef]

33. Mascali, D.; Gambino, N.; Miracoli, R.; Gammino, S.; Torrisi, L.; Maimone, F.; Tumino, L. Plasma parameters measurements by means of Langmuir probe. Radiat. Eff. Defects Solids 2008, 163, 471-478. [CrossRef]

34. Geohegan, D.B.; Puretzky, A.A. Laser ablation plume thermalization dynamics in background gases: Combined imaging, optical absorption and emission spectroscopy, and ion probe measurements. Appl. Surf. Sci. 1996, 96-98, 131-138. [CrossRef]

35. Puretzky, A.A.; Geohegan, D.B.; Fan, X.; Pennycook, S.J. In situ imaging and spectroscopy of single-wall carbon nanotube synthesis by laser vaporization. Appl. Phys. Lett. 2000, 76, 182-184. [CrossRef]

36. Rodríguez-Hernández, P.E.; Quiñones-Galván, J.G.; Meléndez-Lira, M.; Santos-Cruz, J.; Contreras-Puente, G.G.; de Muere Flores, F. Effect of laser fluence on structural and optical properties of CuxS films grown by pulsed laser deposition at different wavelengths. Mat. Res. Express. 2020, 7, 015908. [CrossRef]

37. Ojeda-G-P, A.; Schneider, C.W.; Döbeli, M.; Lippert, T.; Wokaun, A. Plasma plume dynamics, rebound, and recoating of the ablation target in pulsed laser deposition. J. Appl. Phys. 2017, 121, 135306. [CrossRef]

38. Shin, Y.J.; Wang, L.; Kim, Y.; Nahm, H.H.; Lee, D.; Kim, J.R.; Yang, S.M.; Yoon, J.G.; Chung, J.S.; Kim, M.; et al. Oxygen partial pressure during pulsed laser deposition: Deterministic role on thermodynamic stability of atomic termination sequence at $\mathrm{SrRuO}_{3} / \mathrm{BaTiO}_{3}$ interface. ACS Appl. Mater. Interfaces 2017, 9, 27305-27312. [CrossRef] [PubMed]

39. Fominski, V.; Demin, M.; Fominski, D.; Romanov, R.; Goikhman, A.; Maksimova, K. Comparative study of the structure, composition, and electrocatalytic performance of hydrogen evolution in mosx $2+\delta /$ mo and mosx $3+\delta$ films obtained by pulsed laser deposition. Nanomaterials 2020, 10, 201. [CrossRef]

40. Kawaguchi, Y.; Miyazaki, F.; Yamasaki, M.; Yamagata, Y.; Kobayashi, N.; Muraoka, K. Coating qualities deposited using three different thermal spray technologies in relation with temperatures and velocities of spray droplets. Coatings 2017, 7, 27. [CrossRef]

41. Giovannini, A.Z.; Gambino, N.; Rollinger, B.; Abhari, R.S. Angular ion species distribution in droplet-based laser-produced plasmas. J. Appl. Phys. 2015, 117, 033302. [CrossRef]

42. Bulgakov, A.; Bulgakova, N.M. Dynamics of laser-induced plume expansion into an ambient gas during film deposition. J. Phys. D Appl. Phys. 1999, 28, 1710-1718. [CrossRef]

43. Anoop, K.K.; Polek, M.P.; Bruzzese, R.; Amoruso, S.; Harilal, S.S. Multidiagnostic analysis of ion dynamics in ultrafast laser ablation of metals over a large fluence range. J. Appl. Phys. 2015, 117, 083108. [CrossRef]

44. O'Mahony, D.; Lunney, J.; Dumont, T.; Canulescu, S.; Lippert, T.; Wokaun, A. Laser-produced plasma ion characteristics in laser ablation of lithium manganate. Appl. Surf. Sci. 2007, 254, 811-815. [CrossRef]

45. Issac, R.C.; Varier, G.K.; Gopinath, P.; Harilal, S.S.; Nampoori, V.P.N.; Vallabhan, C.P.G. Prompt electron emission and collisional ionization of ambient gas during pulsed laser ablation of silver. Appl. Phys. A Mater. Sci. Process. 1998, 67, 557-561. [CrossRef]

46. Amoruso, S.; Bruzzese, R.; Spinelli, N.; Velotta, R.; Vitiello, M.; Wang, X. Dynamics of laser-ablated MgB2 plasma expanding in argon probed by optical emission spectroscopy. Phys. Rev. B 2003, 67, 224503. [CrossRef]

47. Krása, J.; Jungwirth, K.; Gammino, S.; Krouský, E.; Láska, L.; Lorusso, A.; Nassisi, V.; Pfeifer, M.; Rohlena, K.; Torrisi, L.; et al. Partial currents of ion species in an expanding laser-created plasma. Vacuum 2008, 83, 180-184. [CrossRef]

48. Torrisi, L.; Gammino, S. Method for the calculation of electrical field in laser-generated plasma for ion stream production. Rev. Sci. Instrum. 2006, 77, 03B707. [CrossRef]

49. Scharf, T.; Krebs, H.U. Influence of inert gas pressure on deposition rate during pulsed laser deposition. Appl. Phys. A Mater. Sci. Process. 2002, 75, 551-554. [CrossRef]

50. Wang, X.; Zhang, S.; Cheng, X.; Zhu, E.; Hang, W.; Huang, B. Ion kinetic energy distributions in laser-induced plasma. Spectrochim. Acta Part B At. Spectrosc. 2014, 99, 101-114. [CrossRef]

51. Toftmann, B.; Schou, J.; Canulescu, S. Energy distribution of ions produced by laser ablation of silver in vacuum. Appl. Surf. Sci. 2013, 278, 273-277. [CrossRef]

52. Chen, J.; Lippert, T.; Ojeda-G-P, A.; Stender, D.; Schneider, C.W.; Wokaun, A. Langmuir probe measurements and mass spectrometry of plasma plumes generated by laser ablation of $\mathrm{La}_{0.4} \mathrm{Ca}_{0.6} \mathrm{MnO}_{3}$. J. Appl. Phys. 2014, 116, 073303.

53. Zhang, X.; Tang, Z.; Gao, Z. Formation, growth mechanism and packing sequences of binary alloy cluster anions from laser ablation of mixtures of lead and transition metals. Rapid Commun. Mass Spectrom. 2003, 17, 621-626. [CrossRef]

54. Waller, S.E.; Mann, J.E.; Jarrold, C.C. Asymmetric partitioning of metals among cluster anions and cations generated via laser ablation of mixed aluminum/group 6 transition metal targets. J. Phys. Chem. A 2013, 117, 1765-1772. [CrossRef] [PubMed]

55. Assis, M.; Carvalho De Oliveira, M.; Machado, T.R.; Macedo, N.G.; Costa, J.P.C.; Gracia, L.; Andrés, J.; Longo, E. In situ growth of Bi nanoparticles on $\mathrm{NaBiO} 3, \delta$-, and $\beta$-Bi2O3 Surfaces: Electron irradiation and theoretical insights. J. Phys. Chem. C 2019, 123, 5023-5030. [CrossRef]

56. Pira, P.; Burian, T.; Kolpaková, A.; Tichý, M.; Kudrna, P.; Daniš, S.; Juha, L.; Lančok, J.; Vyšín, L.; Civiš, S.; et al. Langmuir probe measurement of the bismuth plasma plume formed by an extreme-ultraviolet pulsed laser. J. Phys. D Appl. Phys. 2014, 47, 405205. [CrossRef]

57. Láska, L.; Krása, J.; Pfeifer, M.; Rohlena, K.; Gammino, S.; Torrisi, L.; Andò, L.; Ciavola, G. Generation of intense streams of metallic ions with a charge state up to 10+ in a laser ion source. Rev. Sci. Instrum. 2004, 75, 1575-1578. [CrossRef] 
58. Nedialkov, N.N.; Imamova, S.E.; Atanasov, P.A. Ablation of metals by ultrashort laser pulses. J. Phys. D Appl. Phys. 2004, 37, 638-643. [CrossRef]

59. Kobayashi, N.; Masumoto, H.; Takahashi, S.; Maekawa, S. Giant dielectric and magnetoelectric responses in insulating nanogranular films at room temperature. Nat. Commun. 2014, 5, 4417. [CrossRef]

60. Almpanis, E.; Pantazopoulos, P.A.; Papanikolaou, N.; Yannopapas, V.; Stefanou, N. Metal nanoparticle arrays on a magnetic garnet film for tunable plasmon-enhanced Faraday rotation. JOSA B 2016, 33, 2609-2616. [CrossRef] 